M. Cardarilli, et al., Int. J. of Safety and Security Eng., Vol. 9, No. 2 (2019) 109-120

\title{
LANDSLIDE RISK MANAGEMENT THROUGH SPATIAL ANALYSIS AND STOCHASTIC PREDICTION FOR TERRITORIAL RESILIENCE EVALUATION
}

\author{
MONICA CARDARILLI ${ }^{1}$, MARA LOMBARDI $^{1} \&$ ANGELO CORAZZA $^{2}$ \\ ${ }^{1}$ Department of Chemical Materials Environmental Engineering, Sapienza University of Rome, Italy. \\ ${ }^{2}$ National Civil Protection Department, Rome, Italy.
}

\begin{abstract}
Natural materials, such as soils, are influenced by many factors acting during their formative and evolutionary process: atmospheric agents, erosion and transport phenomena, sedimentation conditions that give soil properties a non-reducible randomness by using sophisticated survey techniques and technologies. This character is reflected not only in spatial variability of properties which differs from point to point, but also in multivariate correlation as a function of reciprocal distance.

Cognitive enrichment, offered by the response of soils associated with their intrinsic spatial variability, implies an increase in the evaluative capacity of the contributing causes and potential effects in failure phenomena.

Stability analysis of natural slopes is well suited to stochastic treatment of uncertainty which characterized landslide risk. In particular, this study has been applied through a back- analysis procedure to a slope located in Southern Italy that was subject to repeated phenomena of hydrogeological instability (extended for several kilometres in recent years). The back-analysis has been carried out by applying spatial analysis to the controlling factors as well as quantifying the hydrogeological hazard through unbiased estimators.

A natural phenomenon, defined as stochastic process characterized by mutually interacting spatial variables, has led to identify the most critical areas, giving reliability to the scenarios and improving the forecasting content.

Moreover, the phenomenological characterization allows the optimization of the risk levels to the wide territory involved, supporting decision-making process for intervention priorities as well as the effective allocation of the available resources in social, environmental and economic contexts. Keywords: landslide risk, slope stability, soil resilience, spatial variability, susceptibility index.
\end{abstract}

\section{INTRODUCTION}

Worldwide in the last decade, a new vision and collective sensitivity have been affirmed on disaster risk reduction particularly on stability phenomena [1], thanks to institutions and administrations action in territorial planning in which scientific community and research institutes have been providing fundamental support.

Mitigation policy of the impact of hydrogeological events is essentially based on two parallel and coordinated actions: the organization of interventions, which guide social response in emergency contexts and the planning of preventive and protective decisional activities in delayed time. In particular, satellite observation technologies of natural phenomena are increasing for a more successful outcome of preventive land management [2] in quiescent conditions, forecasting the potential effects induced on the areas of interest more accurately.

The increasing availability of data, acquired through modern and sophisticated systems and innovative detection processes, has been associated with application methods and elaborated through numerical modeling aimed at assessing extreme events.

The use of new technologies, associated with a growing safety demand of society, makes the development of integrated technical and scientific methodologies necessary to guide 
predictive spatial planning through a reliable assessment of risk in heterogeneous and dynamic contexts such as those deriving from hydrogeological instability conditions with exogenous (often anthropogenic) origin.

Technological progress and technical-scientific knowledge should lead to improved quantitative analysis by carrying out a reliable probabilistic assessment for characterizing spatial uncertainty and dynamic evolution of potential risk levels. In the same way, this concerns the need to implement a quantitative procedure for the estimation of the variables affecting scenarios in order to reduce risk to a residual value.

These are needs that should meet coordinated investments aiming at synergistic activities to forecast catastrophic events particularly in susceptible territorial contexts either in terms of extension or spatial distribution, considering evolution and duration as well. In fact, enrichment and quantitative cognitive improvement offered by soil response as well as evaluative capacity of potential causes and expected effects should be adapted to the fragility of the specific area.

The development of applied research and technologies for mitigating hydrogeological risk in many countries provides wide and useful tools to achieve a more effective disaster risk reduction [3]. The use of joint methodologies deriving from multi-disciplinary fields and integrated application methods would allow to improve planning and safeguarding activities, giving a comprehensive risk assessment for natural hazards.

A clear advantage is therefore the benefit of a deeper phenomenological knowledge, reorganizing the hydro-geoinformation to complete implementation of procedures to conduct territorial planning and management as well as coordination of urgent interventions.

Common methodologies currently associated with the characterization of instability phenomena of natural soils use semi-probabilistic approaches often neglecting the spatial component. The aleatory uncertainty, belonging to every environmental context, has been recognized as component that may be characterized due to its intrinsic variability, often ignored [4].

A quantitative analysis has been carried out considering the probabilistic distribution of the most influential spatial variables identified. In this way the presence of interdependence and potential mutual correlation of the conditioning parameters may be highlighted.

The acquisition of data and territorial information has been performed by considering different geo-environmental elements such as empirical measurements, instrumental monitoring, historical series and statistical databases, integrated to outline a cognitive framework.

To date, spatio-temporal references concerning mitigation and monitoring are lacking. Planning activities consist of heterogeneous scenarios and unconditional parametric sequences whose predictions do not depend on reliability considerations. The introduction of methodologies, which have long been used in mining field - geostatistics - is therefore essential within a hydrogeological context.

\section{CASE STUDY}

The research was applied to Montaguto, located in Southern Italy, whose earthflow phenomenon have been extended for several kilometres and repeated in recent years (mainly 2006 and 2010); thanks to the wide availability of data and investigations performed to date as well as the large extension of the moving mass and the area involved in the landslide events (downstream crossed by railway and main road infrastructures).

Therefore, the study has been performed in back-analysis by applying spatial analysis to the controlling factors quantifying the landslide hazard through unbiased estimators and indicators. 


\subsection{Geo-territorial setting}

The Montaguto landslide has a length of about $3000 \mathrm{~m}$ and covers an area of $671000 \mathrm{~m}^{2}$. Estimates on the volume define a value of over 6.000 .000 cubic meters and the sliding surface variable between 5 and 6 meters up to 30 meters [5].

The landslide phenomenon of Montaguto is located in a complex morpho-evolutionary system which contains the middle valley of Cervaro torrent and the Dauno Apennines.

The materials involved in the landslide belong mainly to Flysch of Faeto (as shown in Fig. 1), which consists of alternating turbiditic calcarenites, calcilutites and whitish marls, with intercalations of marly clays and bioclastic calcirudites as well as Villamaina deposits constituted by arenaceous-pelitic successions [6].

The phenomenon is characterized by an earthflow evolutionary process with articulated and structurally controlled feeding areas. It is therefore a phenomenon, whose complexity is linked both to dimensional aspect and cinematic-evolutionary processes.

In the Apennine area of interest, the landscape is characterized by the absence of steep morphologies due to the nature of lithotypes: only locally angles of more than $40^{\circ}$ have been observed in correspondence of the most competent outcrops. Therefore, morphologies related to erosional processes are prevalent, while structural forms (layer or fault slopes) are locally present [7].

The predisposing cause of phenomenology is due to litho-structural arrangements of complex sequences (stone-clay alternations) deformed by different tectonic phases. Therefore, conditions, geological and geomorphological structures related to landslide area as well as geo-mechanical and hydrogeological characteristics vary significantly locally and all over due to softening and degradation phenomena [8].

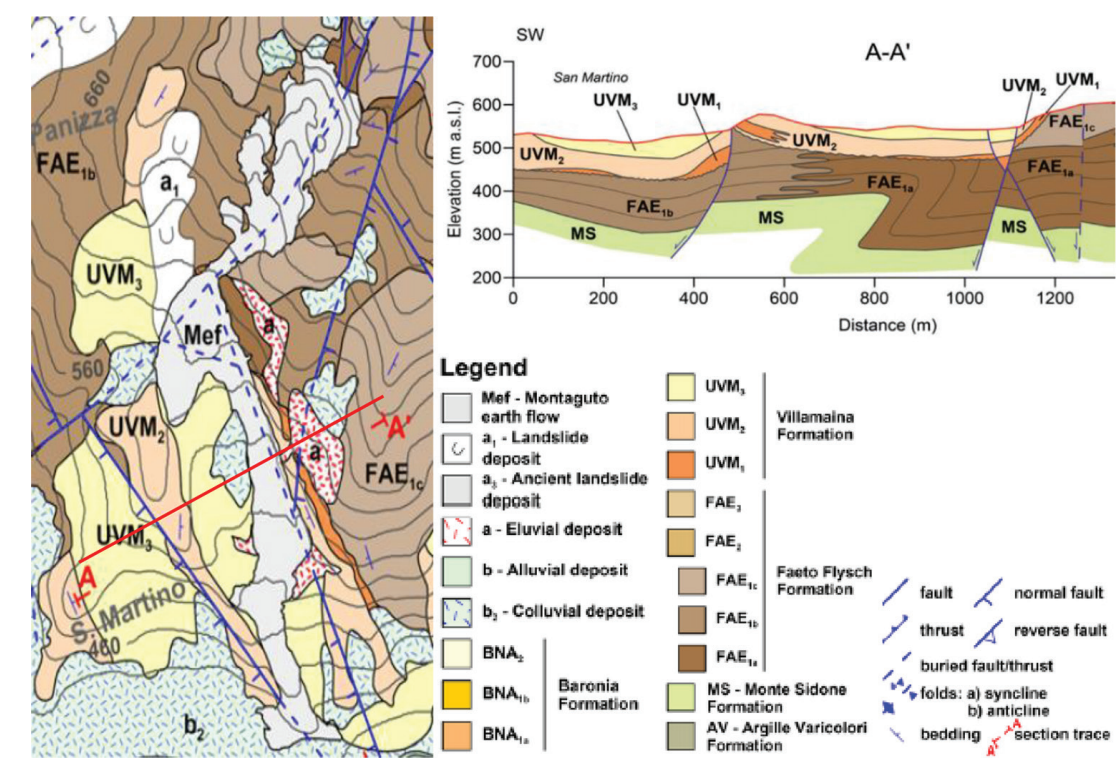

Figure 1: Geological map of the Montaguto earth-flow area based on geological survey at 1:5000 scale (left) with legend (down) and cross-section A-A' (right).

Source: Pinto, 2016. 
The feeding area was affected by heavy rainfall in 2006 and 2010 triggering retrogression phenomena while viscous phenomena were triggered along the escarpment leading to the formation of new deposits. Moreover, in this area some landslide ponds have been formed, fed by springs.

The accumulation area developed downstream where the material achieved a thickness of about $10 \mathrm{~m}$ reaching the foot of the slope. In addition, it led to increasing interstitial pressures induced by soil mobilization and progressive softening [9].

The groundwater circulation raised up discontinuously due to different hydraulic loads.

This would suggest the existence of a main flow, deeper and more relevant in terms of productivity, which has produced Caraventa and Del Ponte sources as well as Panizza and Serracavallo springs with a superficial and less outflow [10].

Given the considerable complexity and extension of the landslide phenomenon it was necessary to identify a smaller area, the accumulation on the toe (Fig. 2), as the most relevant for the purposes, considering also the availability of geological, geomorphological, meteoclimatic data essential for analyzing earthflow phenomena. It is decisive in the landslide evolutionary process as well as its proximity to the road infrastructures located downstream of the slope area.

\subsection{Investigation and monitoring}

The available data were obtained from huge investigation activity, mainly in-situ surveys and monitoring campaigns (Fig. 3), laboratory data and pre-existing cartography as well as WMS database, for the acquisition of further and detailed information.

The collection of technical and scientific material prepared over time by various subjects involved and the availability of near real-time acquisitions are explanatory of how trigger causes and propagation effects are characteristic of heterogeneous and dynamic systems.

The survey campaign required the investigations for lithostratigraphy reconstruction of the area affected by interventions. In addition, in-situ equipments were installed for landslide monitoring.

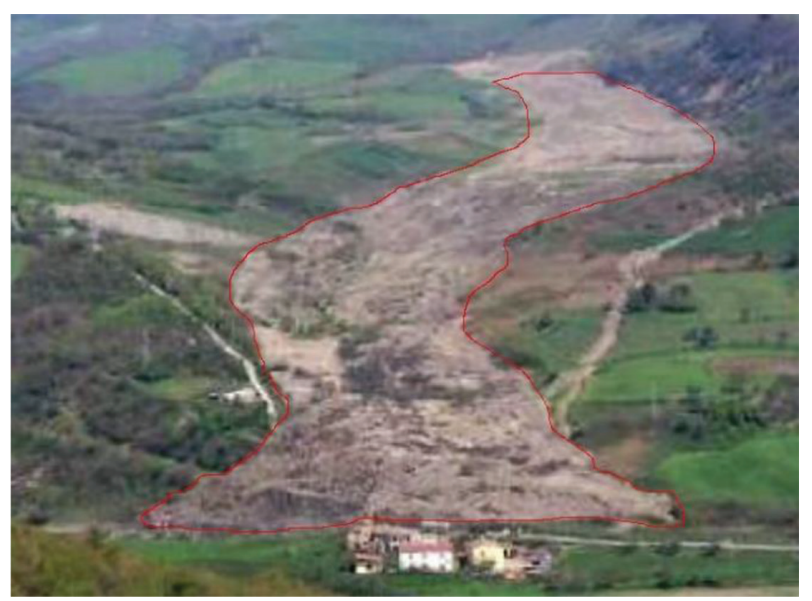

Figure 2: Montaguto earthflow (May 2006), in red the study area. Source: Cascini, 2013. 

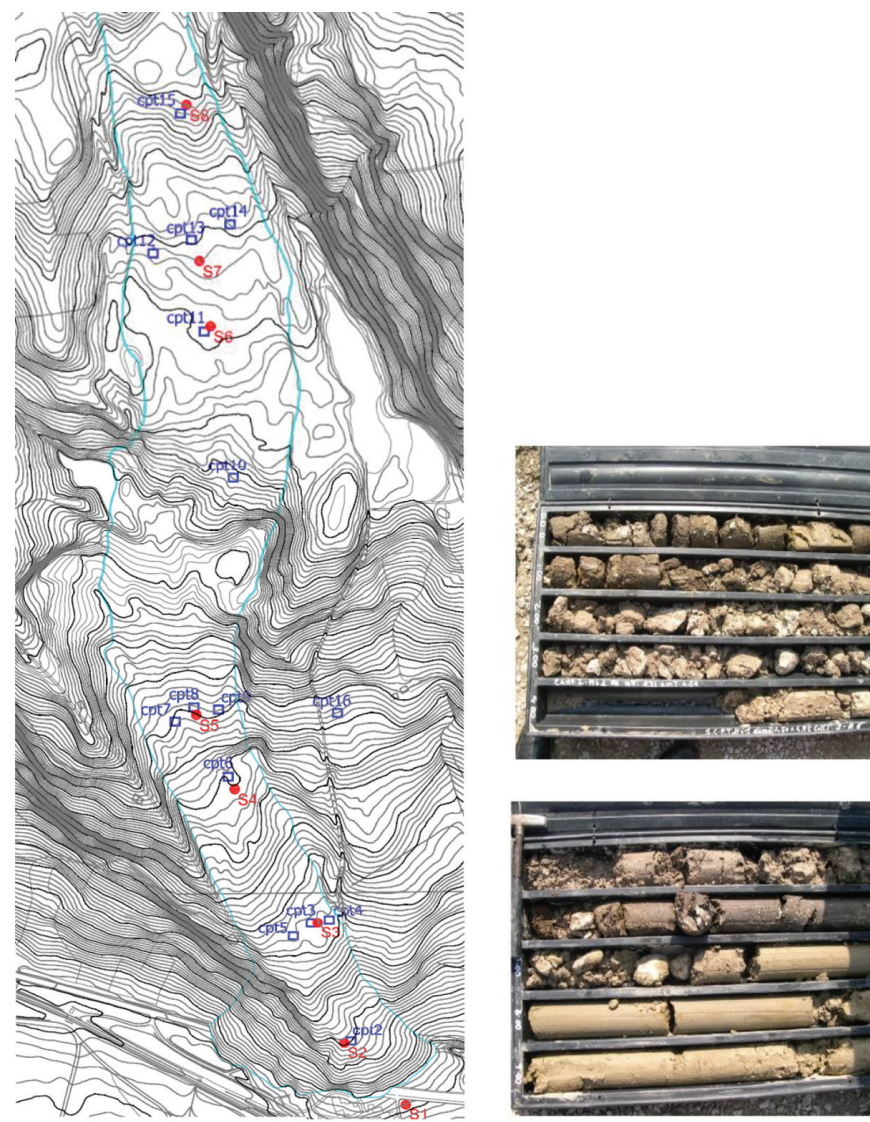

\section{$0-5 m$}

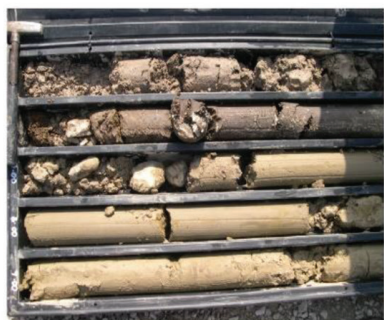

\section{$5-10 m$}

Figure 3: Survey area at 1:5000 scale (left): CPT tests (in blue), geognostic surveys (in red). Carrots extracted during on-site tests up to 10 meters of depth (right).

The investigations proposed were aimed to geotechnical characterization of soil instability as well as the classification of water circulation and the detection of any changes into landslide body. In particular, these surveys have been considered for in-depth analysis in the context of the most recent geological knowledge (after 2000) referring to surveys conducted in 2006 along the accumulation area following the main active landslide event.

In fact, the surveys carried out have highlighted significant differences in term of landslide materials. This depends both on lithotypes distributed along the area as well as alteration processes and softening of the mobilized materials.

As for volumetric characteristics, the analyses carried out to date indicate a significant variability induced by position, condition and nature of sampled soil layers.

\subsection{Susceptibility assessment and prediction}

The first step in the assessment is to define susceptibility as probability of spatial occurrence of a scenario essential to spatial planning. Susceptibility of landslide defines areas with a high potential of developing failure [11]. 
These areas have been identified by correlation between the main factors contributing to potential landslide events (i.e. steep slopes, inconsistent or saturated geological units, poorly drained soil, etc.) as well as distribution and presence of ancient landslides. Their reliability depends above all on quantity and quality of the available data and on the methodology used for evaluating the susceptibility. On the other hand, the working scale also affects the quality of results [12].

The most used methods for zonation of landslide susceptibility may be divided into different groups, in our case we will refer to multivariate statistical method through linear regression method.

Statistical methods seem to be more objective and more suited to analysis at medium and large scales, especially if supported by GIS-based procedures.

The analysis of landslide susceptibility involves data collection, territorial database and identification of factors related to landslide phenomenon.

\subsubsection{Multivariate analysis and soil index}

Quantitative approach has been applied to multiple variables based on multivariate statistical analysis. In this study, a numerical weighting value has been associated per each triggering factor based on its grade of influence on landslide propagation.

In particular, geognostic surveys have been used to classify lithological layers identified by the percentage presence of the following soil classes: clay, silt, sand and gravel, and calibrated through laboratory tests (by undisturbed samples) performed during the same survey campaign. In this way, categorical variables have been associated to each soil class.

A probabilistic analysis was carried out in order to standardize density distributions, making outcomes comparable.

Multivariate statistical analysis was then performed for homogeneous groups of variables (i.e. granulometric characteristics, densimetric and saturation conditions, mechanical behavior, etc.) through the application of conditional linear regression according to depth, evaluating how each category of soil influences the others based on sampling location.

The regression analysis was applied among clay-silt-sand-gravel soil classes obtaining $I_{C S S G}$ index which represents a lithological-geological index and standardized according to the probabilistic curve closest to the empirical trend of sampled values.

On the other hand, $I_{C D S}$ index represents consistency-density-saturation degree, as index of soil thickening obtained from regression analysis (Table 1).

The elaboration of predisposing parameters to obtain quantitative soil indices allows to link geo-environmental factors to susceptibility level then the propensity for landsliding.

Table 1: Measured parameters and percentage composition converted to numerical coding.

\begin{tabular}{ccccc}
\hline Granulometry (C-S-S-G) & Density & Consistency & Saturation & Code \\
\hline 0 & $0-0.2$ & $0-0.5$ & $0-0.2$ & 1 \\
$0-0.05$ & $0.2-0.4$ & $0-0.75$ & $0.2-0.4$ & 2 \\
$0-0.15$ & $0.4-0.6$ & $0.5-0.75$ & $0.2-0.6$ & 3 \\
$0.15-0.25$ & $0.6-0.8$ & $0.5-1$ & $0.4-0.6$ & 4 \\
$0.25-0.35$ & $0.8-1$ & $0.75-1.5$ & $0.4-0.8$ & 5 \\
$0.35-0.5$ & NA & $1-1.5$ & $0.8-1$ & 6 \\
$/$ & $/$ & NA & NA & 7 \\
\hline
\end{tabular}


Geo-mechanical parameters, as quantitative values obtained from in-situ surveys, have been analyzed by applying a standardized approach which would make them comparable with numerical variables.

Similar probabilistic treatment was carried out based on geomorphological and hydrogeological characteristics by weighting the quantitative values considering lithological factors and their propensity towards a potential site-specific triggering phenomenon as well as supported by technical-scientific reference.

Following the linear regression equation (eqn 1) applied to obtain $I_{C S S G}$ index, considering both multivariate and conditioned variables among soil classes. The same has been performed on $I_{C D S}$.

$$
I_{C S S G[x y z]}=\beta_{o}+\beta_{1} C+\beta_{2} S+\beta_{12} C S+\ldots+\beta_{123} C S S+\ldots+\beta_{1234} C S S G
$$

The indices thus obtained were normalized in order to make them comparable with soil strength, such as friction ratio $F s(F s=q c / f s)$, and with measurement of permeability $\mathrm{k}$ obtained from CPTs tests and empirical relations of literature. The following equation (eqn 2) represents all indices obtained which have been combined into a single soil index $\left(I_{\text {soil }}\right)$.

$$
I_{\text {soil }}(\text { measured })_{[x y z]}=I_{C S S G} * I_{C D S} * I_{F s} * I_{k}
$$

The whole index, derived from the combination of predisposing factors, indicates each contribution to local susceptibility within geo-defined units, or globally at all landslide area.

Since geognostic surveys and CPT tests have been performed quiet close in term of mutual distance and no litho-geological discontinuities arose from technical maps, then the outcomes were spatially compared.

\subsubsection{Stochastic spatial estimation}

In geological field, besides the importance of numerical parameters to be studied, data position in space is fundamental. Statistical methods do not take into account spatial information proper to geological data [13].

Geostatistics offers a way to exploit spatial content, allowing also to study spatial continuity as essential aspect of many geological phenomena and for which correlation between two values is as greater as reciprocal spatial distance is smaller.

Geostatistics studies natural phenomena that develop on a spatial basis deriving from sampling information by studying spatial variability of parameters which describe the phenomena. This approach provides solutions to specific problems concerning either spatial characterization or stochastical evaluation of geo-phenomena [14].

Peculiarity of Kriging regression method is the possibility of having, per each estimate, a value which gives a reliability degree to spatial prediction in term of minimal variance of estimation [15]. This allows to define a confidence interval by identifying the areas in which it is necessary to increase the density of investigations (Fig. 4).

Linear spatial regression analysis was performed by applying Kriging as the best stochastic predictor. Kriging considers each observation as a single realization of an aleatory variable whose statistical properties are defined by a variogram function. Starting from available observations, theoretical models have been realized which define spatial variability as well as auto-correlation of the predisposing factors in all three dimensions according to their mutual distance. 


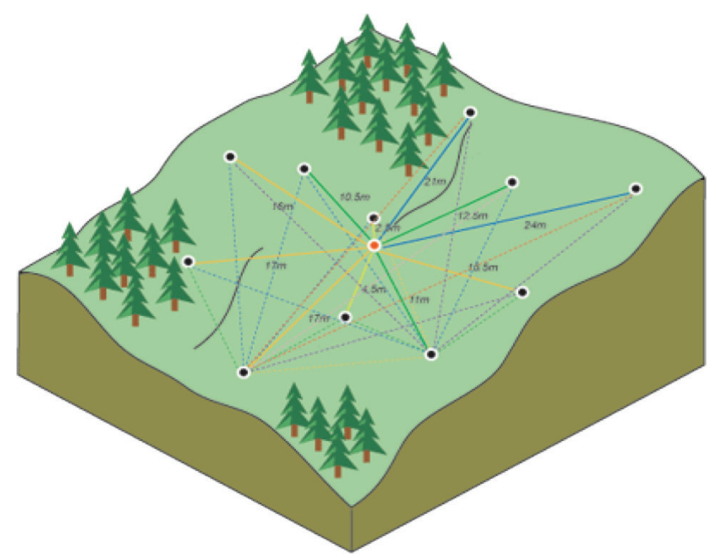

Figure 4: Spatial prediction between unsampled point (in red) and measured locations (black).

Source: http://resources.esri.com

A 3D variogram model has been implemented to all indices conditioning soil instability. Therefore, Universal Kriging (UK) regression model has been applied to the variables providing spatial predictions of the values in points without surveyed information (unknown data). The following predictive maps have been obtained by multiplying values of spatial variability to soil index, as in eqns (3) and (4).

$$
\begin{gathered}
I_{\text {soil }}(\text { predicted })_{[x y z]}=I_{C S S G} * I_{C D S} * I_{F s} * I_{k} \\
I_{s o i l}(\text { variance of prediction })_{[x y z]}=v a r_{C S S G} * v a r_{C D S} * v a r_{F s} * v a r_{k}
\end{gathered}
$$

The three-dimensional spatial maps (Fig. 5) illustrate the spatial distribution of errors associated with Kriging.
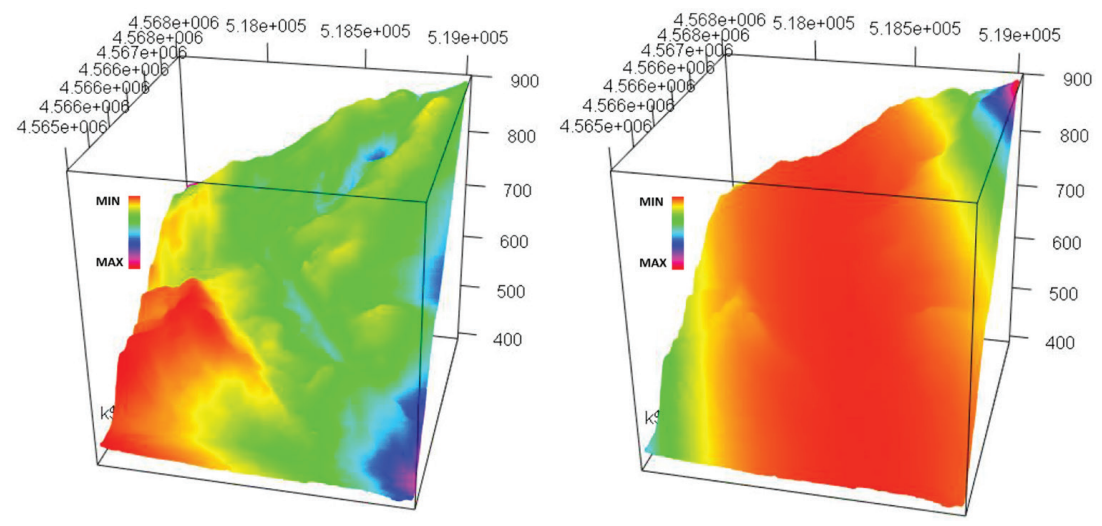

Figure 5: Variability map of spatial predictions (left) and relative variances (right) of soil index. 
Table 2: Range of measured and predicted indices (normalized basis).

\begin{tabular}{lcccc}
\hline & \multicolumn{2}{c}{ Measured } & \multicolumn{2}{c}{ Predicted } \\
\cline { 2 - 5 } & Min & Max & Min & Max \\
\hline$I_{C S S G}$ & 0.568 & 0.893 & 0.424 & 1.000 \\
$I_{C D S}$ & 0.438 & 0.858 & 0.250 & 0.757 \\
$I_{F S}$ & 0.001 & 1.000 & 0.159 & 0.758 \\
$I_{k}$ & $3 \mathrm{E}-10$ & $1 \mathrm{E}+00$ & 0.000 & 1.000 \\
\hline
\end{tabular}

The variability characterized by predictive map detects low values downstream in a localized area while the predictions of variances reflect how estimated values in unknown positions are well-fitted by correlation model then the level of reliability per each predicted value.

The variance map illustrates how higher variances along the left-right side of the landslide body reflect higher distances of the predictions from measured points. Therefore, the estimation variance gives an evaluation in term of ability of Kriging method to accurately estimate uncertainty compared to initial measurements (Table 2).

\section{ERRORS ANALYSIS AND RESULTS}

The main technique used to evaluate the performance of Kriging regression method is the Cross-Validation (CV). It is a useful method, which establishes how well a theoretical model predicts values at unknown locations by calculating the gap with the same measurements. It removes each data per location and predicts the associated value using data located nearby. Thus, repeating the procedure for every measured point, CV compares predicted and observed values obtaining useful information about the quality of Kriging predictions as well as it validates the goodness of fitted variogram model, parameters and neighbourhood.

The following Fig. 6 shows a comparison between the surveyed data of indices $I_{C S S G}$ and $I_{C D S}$, and the estimated outcomes.

In particular, the scatterplot resulting from $\mathrm{CV}$ shows that the smoothness power of Kriging has involved an appreciable overestimation of lower values and a slight underestimation of higher values.
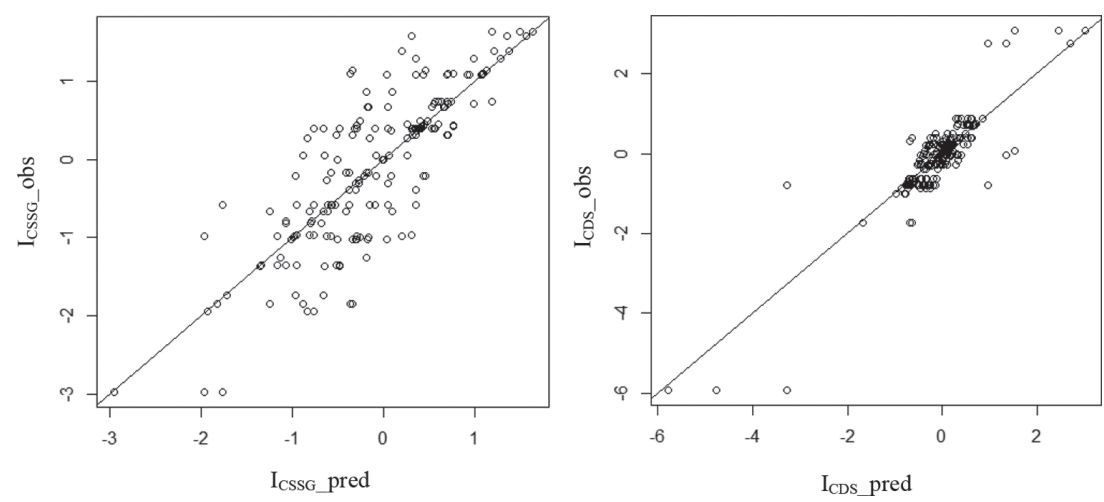

Figure 6: Scatterplot between observed and estimated values of the indices. 
Table 3: Performance criteria between predicted and observed values of the indices.

\begin{tabular}{lll}
\hline & RMSE & MAE \\
\hline$I_{C S S G}$ & 0.133661 & 0.028062 \\
$I_{C D S}$ & 0.123528 & 0.032212 \\
\hline
\end{tabular}

The average of squared standardized errors, as ratio between squared estimation error and variance of predicted value, has given once again a goodness measurement of models and predictions.

RMSE and MAE, shown in Table 3, may be used together to evaluate the variation in errors in a set of predictions. Each of them may range from zero to infinity: lower values indicate better model performance so for the purpose of this study they give acceptable results.

\section{CONCLUSIONS}

Geostatistical analysis involves either statistical techniques or cartographic procedures [16] to obtain 3D-visualization of outcomes obtained by prediction maps for a better understanding of local and global behavior, such as landslide susceptibility, of the phenomenology.

It is fundamental, in fact, the combination of information obtained from elaborations along with cartography carried out on the same case study by some other authors previously. It is a primary requirement the integration between statistical approach and physics-chemicalmechanical studies [17], as they are complementary to obtain susceptibility mapping.

The aim of the estimated variability of experimental data allows to appreciate each contribution to the overall spatial variability for quantitative values both at local and global scale by examining prediction errors associated with spatial interpolation as well as by evaluating spatial model performance.

The results indicate that, for quite uniform and dense sampling locations, Kriging method appears to be well-fitting. It is likely a consequence of the large number of observations, which lessens the influence of extreme values on model calibration and spatial interpolation.

Spatial prediction, based on available data, has enabled interpretation of soil spatial variability which may be used in slope stability assessment as well as in landslide risk management. It is related to all available information on observed values, in particular: to local and punctual assessment, to spatial aleatory uncertainty of parameters as well as to overall soil components and reliability of surveys measurements [18].

Analysis of uncertainty may have potential effects on soil stability for the individuation of failure conditions related to spatial distribution and correlation model.

Relevant outcomes have showed that the proposed technique is endowed with good correlation and accuracy, even when measurement and estimation errors are present.

Kriging mappings highlight that the proposed methods may be applicable with relatively limited data. In addition, the prediction of uncertainty may be described at various levels and scales of soil variability.

This study aims to be a small step forward to the definition of soil resilience, as the ability of a soil to resist or recover its state in response to any natural or anthropogenic perturbations [19], through a cognitive improvement of links and correlations among factors predisposing slope instability in order to reduce failure probabilities thus effects in terms of lives, damage, and negative economic and social consequences. 


\section{REFERENCES}

[1] Almeida, S., Holcombe E.A., Pianosi, F. \& Wagener, T., Dealing with deep uncertainties in landslide modelling for disaster risk reduction under climate change. Natural Hazards and Earth System Sciences, 17(2), pp. 225-241, 2017. https://doi.org/10.5194/ nhess-17-225-2017

[2] Bello, O.M. \& Aina, Y.A., Satellite remote sensing as a tool in disaster management and sustainable development: towards a synergistic approach. Procedia - Social and Behavioral Sciences, 120, pp. 365-373, 2014. https://doi.org/10.1016/j.sbspro.2014.02.114

[3] Qiang, X. \& Zhu, L., Applied research on flood control and disaster reduction based on GIS technology. Muroran Institute of Technology, 59, pp. 73-76, 2010.

[4] Lacasse, S. \& Nadim, F., Uncertainties in characterising soil properties. Publikasjon Norges Geotekniske Institutt, 201, pp. 49+74-75, 1997.

[5] Guerriero, L., Revellino, P., Grelle, G., Fiorillo, F. \& Guadagno, F.M., Landslides and Infrastructures: The case of the Montaguto earth flow in Southern Italy. Italian Journal of Engineering Geology and Environment, 6, pp. 459-466, 2013.

[6] Pinto, F., Guerriero, L., Revellino, P., Grelle, G., Senatore, M.R. \& Guadagno, F.M., Structural and lithostratigraphic controls of earth-flow evolution, Montaguto earth flow, Southern Italy. Journal of the Geological Society, 173, pp. 649-665, 2016.

[7] Guerriero L., Coe, J.A., Revellino, P., Grelle, G., Pinto, F. \& Guadagno, F.M., Influence of slip-surface geometry on earth-flow deformation, Montaguto earth flow, southern Italy. Geomorphology, 219, pp. 285-305, 2014.

[8] Lollino, P., Giordan, D. \& Allasia, P., The Montaguto earthflow: A back-analysis of the process of landslide propagation. Engineering Geology, 170, pp. 66-79, 2014.

[9] Guerriero, L., Diodato, N., Fiorillo, F., Revellino, P., Grelle, G. \& Guadagno, F.M., Reconstruction of long-term earth-flow activity using a hydroclimatological model. Natural Hazards, 77(1), pp. 1-15, 2015.

[10] Giordan, D., Allasia, P., Manconi, A., Baldo, M., Santangelo, M., Cardinali, M., Corazza, A., Albanese, V., Lollino, G. \& Guzzetti, F., Morphological and kinematic evolution of a large earthflow: The Montaguto landslide, southern Italy. Geomorphology, 187, pp. 61-79, 2013.

[11] Soeters, R. \& Van Westen, C.J., Slope stability: recognition, analysis and zonation. Landslide: Investigations and Mitigation, eds. A.K. Turner \& R.L. Schuster, Transportation Research Board - National Research Council, Special Report 247, pp. 129-177, 1996.

[12] Van Westen, C.J., Application of geographic information systems to deterministic landslide hazard zonation. Boletin de Vias, 21(79), pp. 11-141, 1994.

[13] Bhattacharjya, S., Chakraborti, S. \& Das, S., Robust optimization of reinforced concrete folded plate and shell roof structure incorporating parameter uncertainty. Structural Engineering and Mechanics, 56(5), pp. 707-726, 2015. https://doi.org/10.12989/ sem.2015.56.5.707

[14] Lombardi, M., Cardarilli, M. \& Raspa, G., Spatial variability analysis of soil strength to slope stability assessment. Geomechanics and Engineering, 12(3), pp. 483-503, 2017. https://doi.org/10.12989/gae.2017.12.3.483

[15] Goovaerts, P., Geostatistics for natural resource evaluation. Technometrics, 42, 1997.

[16] Heuvelink, G., Kros, J., Reinds, G.J. \& Vries, W.D., Geostatistical prediction and simulation of European soil property maps. Geoderma Regional, 7(2), pp. 201-215, 2016. https://doi.org/10.1016/j.geodrs.2016.04.002 
[17] Cardarilli, M., Guarascio, M. \& Lombardi, M., Preventive planning model for rescue priority management in seismic emergency. International Journal of Safety and Security Engineering, WIT Press, 8, pp. 307-319, 2018. https://doi.org/10.2495/safev8-n2-307-319

[18] Alimonti, C., Lombardi, M., Cardarilli, M. \& Soldo, E., Reliability analysis applied to land subsidence effects of groundwater remediation: probabilistic vs deterministic approach. Water Resources Management, 31(6), pp. 1745-1758, 2017. https://doi.org/10.1007/s11269-017-1596-7

[19] Rattan, L., Restoring soil quality to mitigate soil degradation. Sustainability, 7(5), pp. 5875-5895, 2015. https://doi.org/10.3390/su7055875 